\title{
REHABILITASI SELURUH RAHANG DENGAN PENDEKATAN REORGANISASI PASIEN YANG KEHILANGAN GIGI SEBAGIAN
}

\author{
(FULL MOUTH REHABILITATION WITH REORGANIZED APPROACH IN \\ PARTIALLY EDENTULOUS PATIENT)
}

\author{
Sherman Salim \\ Departemen Prostodonsia \\ Fakultas Kedokteran Gigi, Universitas Airlangga \\ Jl. Mayjend. Prof. Dr. Moestopo No. 47 Surabaya 60132, Indonesia. \\ E-mail: sherman.salim@yahoo.com
}

\begin{abstract}
One of the common dental problems of geriatric patients is missing teeth. Partially edentulous patients with multiple teeth loss are considered to have a kind of disability that is eligible for full mouth rehabilitation. The purpose of this case study was to explore the treatment sequence of reorganized approach when the clinicians provide full mouth rehabilitation with correct imperfections in the occlusion and esthetic in partial dentate patient with unstable occlusion. A male patient aged 55 years came to the Dental Hospital Faculty of Dentistry, Airlangga University with complaints: difficult to chew food and want to improve the appearance of frontal teeth. The management of this case began with a preliminary treatment tartar cleaning the upper and lower jaw, endodontic treatment and tooth extraction. Rehabilitation was then performed around the jaw. In conclusion, rehabilitation care throughout the patient's jaw has been successful clinically, but is still necessary to evaluate the long-term.
\end{abstract}

Key words: full mouth rehabilitation, reorganized approach, partially edentulous

\begin{abstract}
Abstrak
Salah satu masalah gigi yang umum terjadi pada pasien geriatri adalah kasus kehilangan gigi. Pasien-pasien yang mengalami kehilangan sebagian giginya dalam jumlah yang cukup banyak dianggap mempunyai kelainan atau cacat yang perlu untuk dilakukan rehabilitasi seluruh rahang. Tujuan studi kasus ini adalah untuk mengeksplorasi tahapan perawatan dengan pendekatan reorganisasi ketika dokter gigi melakukan rehabilitasi seluruh rahang dengan oklusi dan estetik yang sempurna pada pasien kehilangan gigi sebagian dan oklusi yang tidak stabil. Seorang pasien laki-laki umur 55 tahun datang ke klinik Rumah Sakit Gigi dan Mulut (RSGM) Fakultas Kedokteran Gigi Universitas Airlangga dengan keluhan sulit untuk mengunyah makanan serta ingin memperbaiki penampilan gigi depannya. Tata laksana kasus ini dimulai dengan perawatan pendahuluan berupa pembersihan karang gigi pada rahang atas dan bawah, perawatan endodontik dan pencabutan gigi. Selanjutnya dilakukan rehabilitasi seluruh rahang. Kesimpulan, perawatan rehabilitasi seluruh rahang pada pasien ini telah berhasil secara klinis, namun, masih perlu dilakukan evaluasi jangka panjang.
\end{abstract}

Kata kunci: rehabilitasi seluruh rahang, pendekatan reorganisasi, kehilangan gigi sebagian

\section{PENDAHULUAN}

Salah satu masalah gigi yang umum terjadi pada pasien geriatri adalah kasus kehilangan gigi. Pasienpasien yang mengalami kehilangan sebagian giginya dalam jumlah yang cukup banyak dianggap mempunyai kelainan atau cacat yang perlu untuk dilakukan rehabilitasi seluruh rahang. ${ }^{1}$ Rehabilitasi seluruh rahang terus menjadi tantangan terbesar bagi setiap dokter gigi khususnya dalam kedokteran gigi prostetik. Hal ini membutuhkan diagnosis yang efisien dan rencana perawatan yang tepat untuk memperoleh kontak oklusi dan artikulasi yang harmonis sehingga diperoleh fungsi stomatognati yang optimal, kesehatan dan estetik yang akan memberikan kenyamanan dan kepuasan bagi pasien. Rehabilitasi seluruh rahang tidak dapat dilakukan secara sederhana hanya dengan mengikuti instruksi manual. 
Setiap kasus berbeda, yang mencerminkan keragaman bentuk dan kondisi gigi serta hubungan diantara keduanya. ${ }^{2}$

Salah satu tantangan dalam memprediksi hasil perawatan kedokteran gigi prostetik adalah dengan mengetahui hasil akhir sebelum memulai perawatan. Beberapa teknik rehabilitasi seluruh rahang telah tersedia dan sebagai klinisi harus mampu membuat suatu diagnosis secara komprehensif mengenai kondisi klinis pasien dengan mempertimbangkan kesehatan rongga mulut, fungsi, kenyamanan, dan estetik pasien. Pada kasus tidak ada hubungan oklusi yang stabil, oleh karena gigi yang ada telah rusak parah atau pasien dengan kehilangan gigi sebagian, maka sangat diperlukan suatu pendekatan reorganized. ${ }^{3}$ Pendekatan reorganized adalah suatu cara di mana dokter gigi dapat melakukan teknik oklusi tertentu yang mempunyai resiko menyebabkan gangguan pada sendi dan otot jauh lebih kecil. Hal ini digunakan ketika terjadi perubahan yang signifikan pada oklusi pasien. ${ }^{4}$

Melakukan pendekatan reorganized oklusi membutuhkan keterampilan dan pengetahuan dokter gigi dan teknisi untuk memperoleh hasil yang baik. Suatu oklusi posterior dapat dikatakan stabil apabila tidak ada gangguan gerakan protrusif dan lateral mandibula. ${ }^{5}$ Tujuan perawatan oklusi adalah untuk menyeimbangkan tekanan pengunyahan untuk mencegah kontak tidak merata dan berlebihan pada gigi. $^{6}$

Kebanyakan tindakan kedokteran gigi bidang prostodonsia memiliki potensi untuk menyebabkan perubahan oklusi pasien. Dokter gigi harus menghindari perubahan oklusi yang tidak dikehendaki, karena dapat menyebabkan masalah iatrogenik atau kegagalan restorasi. ${ }^{7}$ Kesehatan mulut yang optimal harus menjadi tujuan utama semua prosedur rehabilitasi oleh karena tujuan akhir perawatan adalah mengembalikan fungsi dan kesehatan rongga mulut pasien serta mempertahankan kondisi tersebut sepanjang masa hidup pasien. ${ }^{8}$ Tujuan studi kasus ini adalah untuk mengeksplorasi tahapan perawatan dengan pendekatan reorganized ketika dokter gigi melakukan rehabilitasi seluruh rahang dengan oklusi dan estetik yang sempurna pada pasien kehilangan gigi sebagian dan oklusi yang tidak stabil.

\section{KASUS}

Seorang pasien laki-laki umur 55 tahun datang ke klinik Rumah Sakit Gigi dan Mulut (RSGM) Fakultas Kedokteran Gigi Universitas Airlangga dengan keluhan kesulitan untuk mengunyah makanan serta ingin memperbaiki penampilan gigi depannya. Pasien belum pernah memakai gigi tiruan serta tidak ada keluhan pada sendi temporomandibula. Tidak ada penyakit sistemik dan dalam keadaan sehat.

Pemeriksaan ekstra-oral, tidak ada keluhan pada sendi temporomandibula dan uji dengan bimanual manipulation tidak ada keluhan nyeri. Pemeriksaan intra-oral menunjukkan adanya posterior bite collapse kanan dan kiri serta oklusi hanya pada regio insisif disertai karies pada daerah servikal gigi 11, 22, 26, 33, 34, 43, dan 44 (Gambar 1-3). Oklusi dinamisnya tidak dapat ditentukan. Overjet dan overbitenya $2 \mathrm{~mm}$.

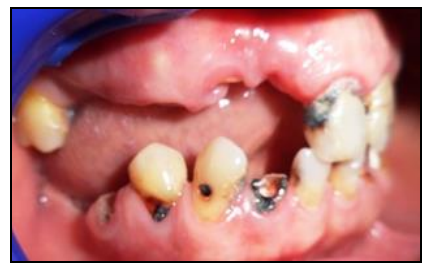

Gambar 1. Posterior bite collapse pada regio kanan

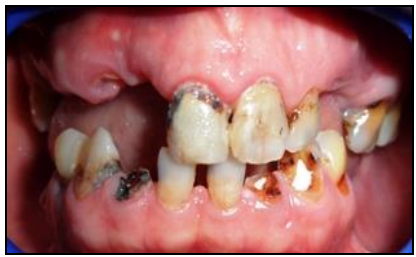

Gambar 2. Oklusi hanya pada regio insisif

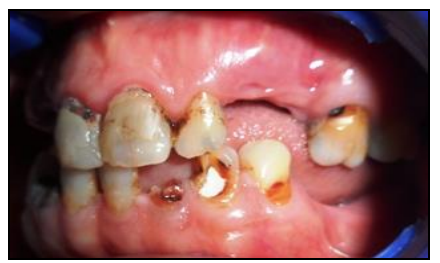

Gambar 3. Posterior bite collapse pada regio kiri

Pemeriksaan radiologis, menunjukkan adanya sisa akar pada 14, 13, 12, 32, 42, dan 45. Gigi 21 dan 12 tampak radiopak pada saluran akar. Radiolusen berbatas jelas pada daerah apikal 13 dan 45 .

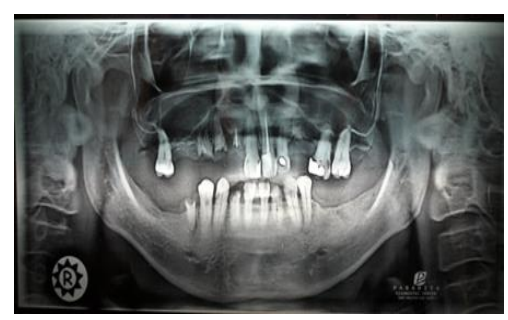

Gambar 4. Foto panoramik menunjukkan adanya gambaran sisa akar 14,13,12,32,42, dan 45. Radiolusen berbatas jelas 13 dan 45, sekunder karies 26, dan post root canal treatment 12 dan 21 
Berdasarkan anamnesis, pemeriksaan klinis dan radiologis, maka diagnosisnya adalah gigi hilang pada $15,16,18,23,24,25,28,35,36,37,38,46$, 47, dan 48; periodontitis apikalis kronis pada 14, 22, 26, 32, 33, dan 42; dental granuloma pada 13, dan 45; pulpitis reversibel pada $17,26,31,34,41,43$, dan 44; post root canal treatment pada 12 dan 22.

\section{PENATALAKSANAAN KASUS}

Tata laksana kasus ini dimulai dengan perawatan pendahuluan berupa pembersihan karang gigi pada rahang atas dan bawah, perawatan endodontik pada gigi $22,32,33$, dan 42 , pencabutan gigi pada 12,13 , 14, 26, dan 45. Setelah selesai, dilakukan pemeriksaan kestabilan otot pengunyahan dan sendi temporomandibula (evaluasi fungsional), pengukuran dimensi vertikal oklusi. Dilanjutkan dengan membuat transitional denture dengan bantuan facebow transfer dan semiadjustable articulator memakai catatan gigit berdasarkan relasi sentrik (centric relation/CR) (Gambar 5, 6, 7, dan 8). Setelah pemasangan transitional denture, dilanjutkan dengan membuat diagnostic wax-up rahang atas dan bawah (Gambar 9). Selanjutnya dilakukan pengasahan gigi rahang bawah (Gambar 10), pencetakan, pembuatan dan pemasangan mahkota sementara berdasarkan diagnostic wax-up, pembuatan restorasi definitif, dan pemasangan sementara restorasi definitif rahang bawah. Setelah evaluasi oklusi, dilakukan pengasahan gigi rahang atas (Gambar 11), pencetakan, pemasangan mahkota sementara, pembuatan restorasi definitif (Gambar 12 dan 13). Pemasangan sementara restorasi definitif rahang atas, dan dilakukan evaluasi dengan memeriksa kestabilan otot pengunyahan dan sendi temporomandibula, dimensi vertikal oklusi, intra-oral, dan fonetik.

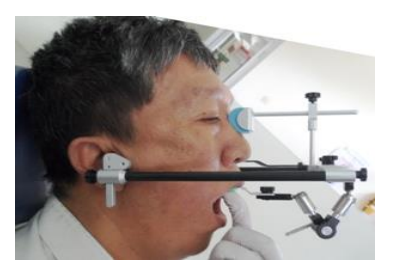

Gambar 5. Face-bow pada pasien

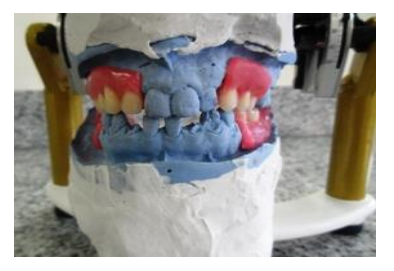

Gambar 6. Transitional denture pada semiadjustable articulator

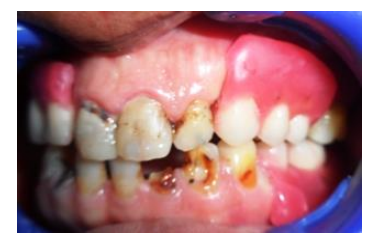

Gambar 7. Model malam transitional denture dalam rongga mulut

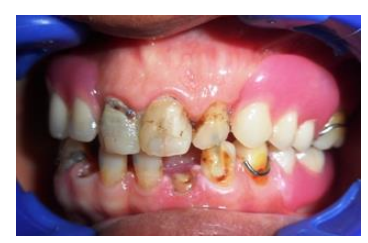

Gambar 8. Transitional denture dalam rongga mulut

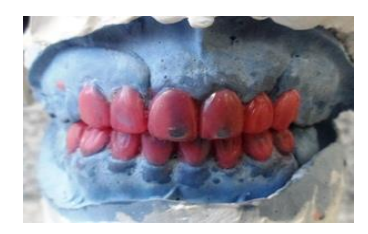

Gambar 9. Diagnostic wax-up

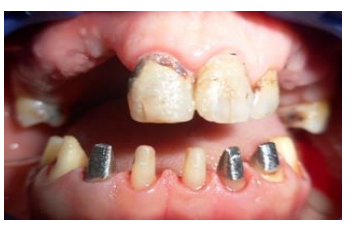

Gambar 10. Pengasahan gigi-gigi rahang bawah

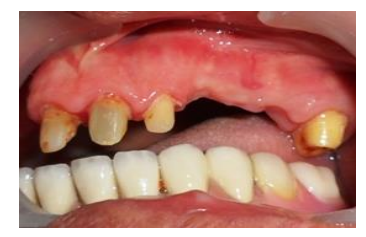

Gambar 11. Pengasahan gigi-gigi rahang atas

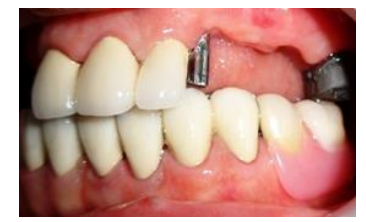

Gambar 12. Gigi tiruan tetap metal-ceramic rahang atas

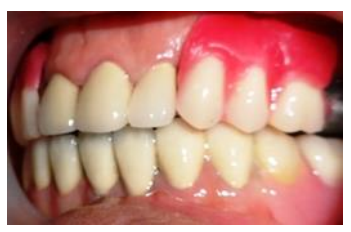

Gambar 13. Model malam restorasi definitif dalam rongga mulut 


\section{HASIL}

Rehabilitasi seluruh rahang pada pasien ini berupa restorasi complex denture memakai retensi attachment dengan pola oklusi mutually protected occlusion (canine guidance) dan dimensi vertikal oklusi yang baru, serta oklusi hasil perawatan yang stabil setelah satu tahun pemasangan tetap restorasi definitif (Gambar 14, 15 dan 16).

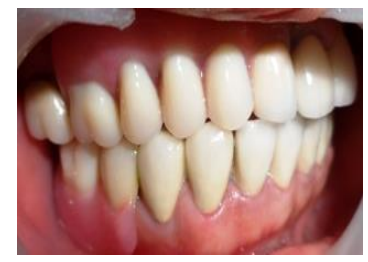

Gambar 14. Restorasi definitif tampak sisi kanan

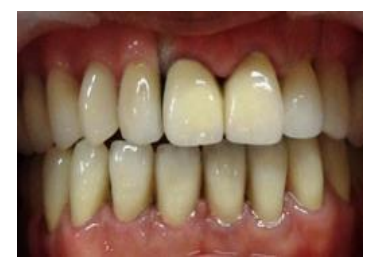

Gambar 15. Restorasi definitif tampak depan

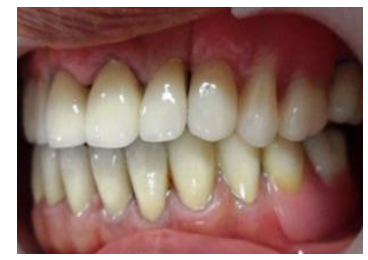

Gambar 16. Restorasi definitif tampak sisi kiri

\section{PEMBAHASAN}

Pada kasus ini, pasien mempunyai oklusi dan dimensi vertikal oklusi yang tidak stabil sehingga pada rencana perawatannya diperlukan perbaikan pada seluruh rahang dengan pendekatan reorganized. Hal ini sesuai dengan hasil penelitian yang menyatakan bahwa pendekatan reorganized diperlukan untuk perbaikan oklusi yang melibatkan perbaikan dimensi vertikal oklusi dengan tujuan untuk mendapatkan oklusi yang lebih stabil sehingga dapat ditoleransi oleh sistem neuromuscular pasien sepanjang hidupnya. ${ }^{7}$ Prinsip-prinsip dasar oklusi dan aplikasinya merupakan faktor penting untuk menentukan keberhasilan perawatan prostodontik dengan pendekatan reorganized. Beberapa literatur telah menyebutkan prinsip-prinsip pendekatan reorganized. Tiga prinsip yang telah digunakan yaitu membuat oklusi baru dengan posisi yang stabil, menentukan dimensi vertikal oklusi dan membuat kedudukan intercuspal position (ICP) yang stabil serta mencegah kerusakan pada pergerakan rahang bawah. Sedangkan tahap perawatannya ada empat yaitu mendapatkan kestabilan oklusi gigi posterior, anterior guidance pada restorasi sementara, menjiplak anterior guidance tersebut untuk restorasi definitif, dan memasang restorasi definitif. ${ }^{2}$ Empat prinsip lain yaitu ñEDECò E (examine the existing occlusion), D (design the new occlusion), E (executing the planned new occlusion and jaw relationship) dan $\mathrm{C}$ (checking that the definitif restorations conforms to the occlusion that has been designned and executed in the previous phases). ${ }^{7}$

Pendekatan reorganized pada kasus ini memakai prinsip yang telah dilakukan oleh peneliti sebelumnya ${ }^{7}$, pada tahap awal (E) memeriksa oklusi dan evaluasi fungsional. Evaluasi fungsional ini merupakan syarat yang harus dilakukan pada setiap perawatan prostodontik agar didapatkan perawatan prostodontik yang tepat dan memuaskan. ${ }^{9,10}$ Evaluasi ini dapat menentukan derajad disfungsi, perubahan pergerakan rahang bawah atau nyeri wajah pada masing-masing individu. ${ }^{9,11}$ Pada anamnesis, pasien tidak mempunyai keluhan pada sendi temporomandibula maupun otot-otot pengunyahannya. Pada evaluasi fungsional tidak ada keluhan nyeri dan relatif normal, dan kondisi sendi temporomandibula juga stabil karena pada bimanual manipulation tidak ada keluhan nyeri. Pemeriksaan ini mutlak dilakukan karena pada perawatan ini penderita harus dapat mencapai kedudukan CR dan untuk mendapatkan kedudukan tersebut, salah satu cara yang dipakai adalah bimanual manipulation. ${ }^{11,12} \mathrm{Ke}-$ dudukan CR ini akan dipakai sebagai kedudukan oklusi yang baru karena penderita tidak mempunyai kedudukan ICP yang stabil.

Kedudukan sendi temporomandibula yang relatif stabil pada pasien, maka pemasangan splint tidak diperlukan, namun langsung pemasangan transitionnal denture memakai oklusi baru berdasarkan kedudukan CR dengan bantuan face-bow transfer dan semiadjustable articulator. Tahap ini merupakan tahap kedua prinsip Wassel dkk yaitu ñDò Pada tahap selanjutnya yaitu r̃Eò dilakukan dengan membuat diagnostic wax-up dengan memperhatikan oklusi gigi posterior dan anterior guidance. Hal ini diperlukan karena rencana perawatannya adalah mendapatkan oklusi dinamik berupa mutually protected occlusion/MPO atau canine guidance. Kasus ini memakai pola oklusi dinamik MPO karena beberapa literatur menyebutkan bahwa pola oklusi tersebut merupakan pola oklusi yang relatif paling aman untuk sendi temporomandibula. Hal ini disebabkan karena tidak adanya kontak pada gigi-gigi posterior saat pergerakan rahang bawah ke lateral 
dan anterior, sehingga tidak ada kontak prematur. ${ }^{12}$

Pada tahap selanjutnya, membuat restorasi definetif berdasarkan keadaan oklusi, bentuk anatomi gigi anterior, anterior guidance maupun dimensi vertikal oklusi restorasi sementara. Beberapa literatur menyebutkan bahwa restorasi seluruh rahang dengan pendekatan reorganized sebaiknya dimulai dari gigi-gigi posterior untuk mendapatkan kontak ICP yang stabil. ${ }^{2}$ Namun pada kasus ini, pembuatan restorasi definitif berdasarkan prinsip dari Dawson untuk tata laksana perawatan seluruh rahang pada gigi-gigi yang mengalami atrisi berat. Prinsip pembuatan restorasi dimulai dari gigi-gigi anterior rahang atas atau rahang bawah. Tujuannya adalah untuk mendapatkan anterior guidance pola oklusi dinamik MPO lebih dulu, setelah itu pola oklusi gigi-gigi posterior mengikuti pola anterior guidance yang telah dibentuk pada semi adjustable articulator. Hal ini juga sesuai dengan prinsip dari Starr yaitu untuk mendapatkan pola oklusi yang stabil, sebaiknya membagi gigi-gigi menjadi komponen anterior dan posterior dan lebih diutamakan kepentingan fungsionalnya terlebih dulu. ${ }^{13}$

Restorasi definitif kasus ini berupa complex denture memakai retensi extra-coronal attachment dengan tujuan untuk estetik. Pada gigi 17 dan 27, retensinya berupa telescope double crown dengan friction-free element. Hal ini disebabkan karena hasil pemeriksaan radiologis menunjukkan akar pada gigi-gigi tersebut berupa akar tunggal, sehingga relatif kurang kuat untuk gigi penyangga dengan retensi extra-coronal attachment. Pemakaian telescope double crown dengan friction-free element akan dapat meneruskan daya kunyah searah dengan sumbu akar gigi tersebut, dan friction-free element akan berfungsi sebagai stress-breaker. ${ }^{14}$ Namun, yang harus diperhatikan pada setiap pemasangan attachment adalah informasi tentang cara menjaga kebersihannya dan kontrol secara rutin karena plastic cap attachment harus diganti setahun sekali. Sebagai kesimpulan pada kasus ini, hasilnya menunjukkan load test negatif, clench test negatif, grinding test tidak ada kontak prematur pada gigi posterior, fremitus test negatif, stability test negatif, comfort test memberikan rasa nyaman pada gigi, bibir, dan wajah serta tidak ada gangguan fungsi bicara, dan mengunyah, dan esthetic test penderita merasa senang dengan penampilan hasil perawatan baik saat istirahat maupun tersenyum, jarak inter cemento-enamel junction (inter CEJ) gigi insisif pertama tetap setelah satu tahun pemasangan tetap. Hal ini menunjukkan bahwa perawatan rehabilitasi seluruh rahang pada pasien ini telah berhasil secara klinis. Namun, masih perlu dilakukan evaluasi jangka panjang.

\section{Daftar Pustaka}

1. Katsoulis J, Nikitovic SG, Spreng S, Neuhaus K, Mericske-Stern R. Prosthetic rehabilitation and treatment outcome of partially edentulous patients with severe tooth wear: 3-years result. J Dent 2011; 39: 662-71.

2. Wassel R, Naru A, Steele J, Nohl F. Applied occlusion. United Kingdom: Quintessence Publ Co. Ltd., 2008: 31-48.

3. Johansson A, Johansson AK, Omar R, Carlsson GE. Rehabilitation of the worn dentition. J Oral Rehabil 2008; 35: 548-66.

4. Attin T, Filli T, Imfeld C, Schmidlin PR. Composite vertical bite reconstructions in eroded dentitions after 5.5 years: a case series. J Oral Rehabil 2011; 39(1): 73-9.

5. Raigrodski AJ, Dogan S. Concepts and considerations of tooth wear. II. The mechanical component. Practical Procedures \& Aesthetic Dentistry 2008; 20: 220.

6. Di Matteo AM. Pounding on the occlusion pulpit. Inside Dentistry 2008; 4(3): 102-10.

7. Burke FJ, Kelleher MG, Wilson N, Bishop K. Introducing the concept of pragmatic esthetics, with special reference to the treatment of tooth wear. J Esthet Restor Dent 2011; 23(5): 277-93.

8. Sudhir N and Parkash H. Full mouth rehabilitation with group function occlusal scheme in a patient with severe dental fluorosis. Indian Journal of Dental Advancements 2011; 3(3): 627-31.

9. Preti G. Prosthetic rehabilitation. United Kingdom: Quintessence Co. Ltd., 2008: 43-57.

10. Becker IM. Comprehensive occlusal concepts in clinical practice. United States: Wiley-Blackwell; 2011: 6-9.

11. Okeson JP. Management of temporomandibular disorders and occlusion. $6^{\text {th }}$ ed., St. Louis, Missouri: Mosby Elsevier Inc., 2013: 181-202, 233.

12. Dawson PE. Functional occlusion: From TMJ to smile design. St. Louis, Missouri: Mosby Elsevier Inc., 2007: 91-2, 436-9, 595-602.

13. Starr NL. Establishing a stable occlusal scheme. In Cohen M. Interdisciplinary treatment planning. Principles, design, implementation. Hanover: Quintessence Publishing Co, Inc., 2008: 313-31.

14. Wulfes H, Deselaers R, Forster S, Marbach O, Rietmuller M. Telescopic double crowns: Individual solution: Practical and economical. Academia Dental International School BEGO Germany, 2009: 60, 81-8.

15. Joseph BB, Nakamura S, Freedman AL, Yalisove IL. Telescopic retainers: An old or new solution? A second chance to have normal dental function. $\mathbf{J}$ Prosthodont 2012; 21: 79-83. 